\title{
PROCESSO PRODUTIVO \\ E VISÃO DO TRABALHO \\ ENTRE SUPERVISORES \\ DE UMA EMPRESA AUTOMOBILÍSTICA
}

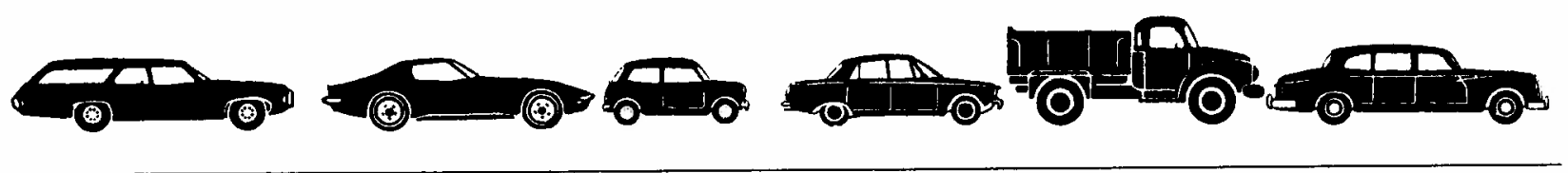

\section{- ARAKCY MARTINS RODRIGUES}

Professora Titular de Psicologia no Departamento de

Fundamentos Sociais e Jurídicos da Administração da EAESP/FGV

Trabalho apresentado originalmente ao Grupo

de Trabalho "Processo de Trabalho e Reivindicaçōes

Sociais" do IX Encontro Anual

da ANPOCS - Associação Nacional de

Pós-Graduação e Pesquisa em Ciências Sociais -

realizado em outubro de 1985, em Águas de

S. Pedro, SP.

\section{INTRODUÇÃO}

A o estudarmos os processos produtivos, tendemos a adotar categorias seguindo geralmente uma (ou uma combinação) das classificações abaixo:

a) setor (primário, secundário, terciário);

b) ramo de atividade;

c) grau de desenvolvimento tecnológico para os diferentes setores e ramos, grau de mecanização ou automatização presentes no processo de transformação;

d) departamento interno da empresa - pessoal ligado à produção, administração, supervisão, etc. (1);

e) nível hierárquico dentro da organização.

Trabalhos recentes, que tomam como uma referência importante o processo produtivo, vêm se preocupando em encontrar, entre os cargos individuais, aqueles que diferem significativamente de todo o restante da linha por apresentarem exigências que requisitam do executante o desempenho de uma tarefa qualificada. No pólo extremo de um continuum de qualificação pessoal, encontramos os casos em que a habilidade necessária ao desempenho da tarefa assume as características de um "dom" adquirido, não se sabe como, pelo seu portador. Incluem-se nessa categoria os indivíduos que, num determinado momento do processo produtivo, devem decidir sobre a temperatura da matéria-prima pelo tato, o "ponto" da mistura pelo olfato, a correção dos tons de cor pela visão. Uma atividade, portanto, não fragmentável, não especificável, não treinável, não cronometrável.

No âmbito da produção industrial, comparece, principalmente em trabalhos sobre a indústria automobilística, uma discriminação relevante entre operários: a que distingue, como grupo mais qualificado e criativo, os ferramenteiros ${ }^{(2)}$.

Ao estudarmos as representações de um grupo de supervisores sobre o trabalho, num levantamento qualitativo que tinha o objetivo básico de fornecer subsídios para uma pesquisa quantitativa numa grande montadora de automóveis de São Paulo, deparamo-nos com um divisor de águas não esperado (e, conseqüentemente, não trabalhado devidamente na escolha dos componentes da pequena amostra): os discursos dos supervisores apresentavam sensíveis diferenças entre os alocados na "linha" e aqueles que trabalhavam na manuten-

1. Há casos em que os estudiosos emprestam a terminologia local das próprias organizaçóes, adotando as categorias horista/mensalista ou as que designam departamentos intraorganizacionais: produção, escritório, vendas, etc.

2. A crescente transferência de tecnologia e a introdução de padrōes para presidir essa tarefa vêm relativizando, nos últimos anos, a imagem deixada em períodos anteriores pelos estudiosos do assunto. 
ção; complementarmente, fazia-se notar uma grande semelhança entre as representações dos agentes que compunham cada um dos subgrupos. O número reduzido de supervisores de controle de qualidade, de ferramentaria e de segurança que vieram a integrar nossa pequena amostra (um caso em cada um dos tipos) não nos permite falar desses subgrupos com a mesma força que utilizamos nas afirmações feitas em relação aos de manutenção e de produção. Entretanto, é possível sugerir a hipótese de que o tipo de tarefa a que se dedicam os supervisores pesquisados é parâmetro importante no que se refere à explicação das diferenças encontradas entre as suas representações, que analisaremos a seguir.

Os discursos dos supervisores de controle de qualidade e de ferramentaria podem ser localizados, figurativamente, em posições intermediárias nesse espaço gerado pelas diferenças entre as representações dos supervisores de produção e de manutenção. Os supervisores de segurança nos parecem muito próximos dos de produção, apresentando, muitas vezes, em tintas mais carregadas, o tipo de disposições desses em relação ao trabalho e à empresa.

As representações diferenciais detectadas entre os supervisores de manutenção e os de produção encontram suas possíveis determinações em algumas variáveis como qualificação, grau de instrução e experiências profissionais anteriores. Entretanto, o vínculo com a tarefa e, em se tratando de supervisão, o significado de "chefia" em cada um dos grupos parecem ser as de maior alcance explicativo. Além disso, qualificação, escolaridade e experiências anteriores constituem requisitos para a alocação do agente no setor de manutenção e para sua ascensão ao nivel de supervisão. Enfatizamos também, na análise, que a qualificação não só é exigida para a admissão e promoção, como está presente no dia-a-dia da tarefa, uma vez que a natureza dessa impede seu planejamento em outras instâncias organizacionais.

\section{METODOLOGIA}

Tanto a parte quantitativa quanto a qualitativa da pesquisa, realizada com o consentimento da empresa, mantiveram em sigilo a identificação dos respondentes. Na coleta do material para o levantamento qualitativo, de que trata este trabalho, os cuidados com esse aspecto foram redobrados: pedimos aos departamentos envolvidos com a pesquisa (Recursos Humanos e Relações Industriais) a listagem de computador com o nome, cargo, nível, idade, escolaridade, endereço dos funcionários, da qual foram escolhidos os funcionários que seriam procurados em seus próprios domicílios, sem que ninguém, dentro da empresa, fosse informado sobre quem seria entrevistado. Considerando o elevado número de funcionários da organização, acreditamos ter realmente impossibilitado qualquer tentativa no sentido de localizar as pessoas cujas opiniões são transcritas na análise.

$\mathrm{Na}$ escolha dos entrevistados potenciais, apesar do reduzido tamanho da amostra e da inexistência de qualquer pretensão de representatividade, cuidamos de diversificar os casos, tomando como referência idade, tempo de casa e escolaridade.

Conforme já mencionamos acima, as diferenças entre supervisores ligados à manutenção, controle de qualidade, ferramentaria, produção e segurança não constavam de nossas preocupaçōes, não tendo, portanto, sido utilizadas como critério de seleção. Entre os treze casos estudados, a distribuição segundo o setor foi a seguinte: seis supervisores de produção, quatro de manutenção, um de controle de qualidade, um de ferramentaria e um de segurança (proteção à fábrica).

A abordagem dos entrevistados seguiu o seguinte procedimento: procurado em sua residência, o supervisor era informado da realização de uma grande pesquisa na empresa. Esclarecia-se que esse estudo constava de duas etapas e que ele poderia ter sido escolhido para mais de uma (preenchimento de questionário, na própria fábrica e a entrevista em profundidade). $O$ entrevistador assegurava o sigilo das informações e pedia consentimento para gravar. Solicitava ao entrevistado que falasse tudo o que tivesse vontade a respeito de seu trabalho, e seguia a norma de não interferência durante a fala do entrevistado. Uma vez esgotado o "discurso livre", aplicava um questionário aberto, contendo indagações sobre as condições objetivas de vida, com o cuidado de não perguntar acerca de temas que tivessem aparecido na fala espontânea anterior.

Como era de se esperar para esse segmento social, a maior parte dos supervisores recebeu com desconfiança o entrevistador. Nesses casos, explicávamos ao entrevistado que poderia se informar na companhia a respeito da existência de uma equipe no campo. Indicávamos um nome, num determinado departamento, que podia ser procurado por telefone. Advertíamos a pessoa sobre o risco de se identificar, e sugeríamos que telefonasse anonimamente (ou pedisse para alguém ligar). Na quase totalidade dos casos, as "provas" representadas por essa fala bastavam para tranquilizar o supervisor, que dava a entrevista em seguida.

\section{ANÁLISE DAS ENTREVISTAS}

a) considerações gerais 
Em primeiro lugar, todas as associaçães e respostas dos agentes devem ser avaliadas à luz dos seguintes fatos:

1. trata-se de uma pesquisa consentida pela companhia, e isso lhes é explicitado;

2. os argumentos oferecidos pelo entrevistador como garantia do anonimato (na pesquisa qualitativa, os pesquisadores sabem seu nome, mas informam que ele não irá aparecer; na pesquisa quantitativa, o respondente do questionário assina uma lista de presença, mas a equipe chama sua atenção para o fato de não assinar o próprio questionário) são de difícil compreensão para quem nunca fez pesquisa e, em alguns casos, são objeto de descrença;

3. entre os mais velhos, existe o medo de serem taxados de "antiquados", aparecendo a necessidade de demonstrarem que são "abertos" às inovações, até mais que os jovens.

Outra questão importante, no caso específico dos supervisores, é a de lembrarmos, sobre todos os temas analisados, o fato de ocuparem uma posição intermediária, à qual chegaram vindo de baixo (com raras exceções), enquanto em outros grupos intermediários (baixa e média gerência, por exemplo) as exceçõesconstituem as ascensões dentro da empresa, constituindo a regra as entradas laterais. Nessa escalada, entretanto, se os operários promovidos a supervisores distanciam-se de seu grupo original, nem por isso logram ingressar de fato nos grupos de poder dentro da organização. Sobre "chefia intermediária" - expressão genérica, utilizada nas organizações e que engloba diferentes títulos ocupacionais num mesmo rótulo - comenta Laura Dantas: "Suficientemente abstrato e, como tal, uma boa marca mercadológica, o rótulo oculta a dimensão técnica, inerente às várias designações, e transmite a idéia de dominação, da palavra chefe, embora adjetivando-a com o qualificativo intermediário, o que adverte sobre a relatividade do poder atribuído a esse tipo especial de chefe"(3).

A ambigüidade quanto à identificação de classe é apontada por Leôncio Martins Rodrigues: "Categoria profissional situada entre a gerência e os operários, os supervisores gostam de se definir como um elo intermediário entre os escalões superiores e inferiores da Companhia. Se administrativamente assim é, socialmente os supervisores constituem a camada superior das camadas inferiores e, politicamente, são os dominantes entre os dominados. Esta situação ambígua, que deriva de sua localização na fronteira entre os horistas e a Companhia, dificulta a própria identificação de classe e sua localização no espaço social entre a 'classe operária' e a 'classe média'. Estes aspectos singularizam, em toda parte, os 'homens de supervisão', prensados entre dois mundos: o da decisão e o da execução, o do comando e o da obediência, o do Capital e o do Trabalho. Esta situação intermediária, própria da supervisão nas indústrias de produção em série e do trabalho parcelado, faz do supervisor um 'homem dividido' "(4).

A análise do material indica grande ambigüidade e divisão interna em relação à maior parte das opiniões emitidas. Acreditamos que essa dubiedade transcende o fato de estarem que-rendo agradar, por um lado, e deixarem escapar o que realmente pensam, de outro lado. Embora possa ser referida parcialmente a esses fatores, quer nos parecer que a visão contraditória e a divisão interna correspondem a níveis mais profundos e se explicam pela sua posição intermediária e sua trajetória, tanto como classe social como enquanto segmento profissional.

Encontramos variações no grau de ambigüidade e maior ou menor identificação com os "de baixo" e com os "de cima", conforme alguns determinantes. Assim, por exemplo, os supervisores com baixa escolaridade, alocados em departamentos de produção e segurança (que não encontram argumentos muito sólidos para sua ascensão) tendem a se identificar mais com os "de baixo". O mesmo ocorre com os mais velhos, com visível medo de serem incluídos nos "pacotões"(5). Como aponta Luc Boltanski, nos momentos de crise profissional os ocupantes de posições intermediárias tendem a apresentar um discurso "proletário"(6). Cinco variáveis parecem muito importantes para a determinação desses índices de ambigüidade: escolaridade, experiências anteriores na própria indústria (principalmente na automobilística), idade, tempo de casa e tipo de tarefa (conseqüente do setor de atuação). Evidentemente, a conjugação específica dessas variáveis desempenha um papel muito mais importante que a soma delas tomadas isoladamente. Ademais, como já foi salientado, as quatro primeiras variáveis constituem importantes requisitos

3. DANTAS, Laura. Ambigüidade e Socialização do Chefe Intermediário Industrial, mimeo.

4. RODRIGUES NETTO, Leôncio Martins. O Trabalhador da Empresa Automobilística. 1 Parte, "Os Supervisores", São Paulo, 1984, mimeo.

5. No momento da realização da pesquisa, corriam na empresa insistentes boatos (parcialmente confirmados mais tarde) sobre a existência de listas de funcionários, notadamente os mais velhos, que seriam convidados a se afastarem da organização, mediante o pagamento de uma determinada quantia em dinheiro. Na gíria local, as listas eram chamadas de "pacotões".

6. BOLTANSKI, Luc. "Les cadres autodidactes", in: Actes de la Recherche en Sciences Sociales, (22): 3-23, junho de 1978. 
para a alocação do supervisor em um determinado setor, que é o quinto dos fatores apontados. Os supervisores de manutenção estão muito mais envolvidos com uma tarefa específica (realizam um trabalho concreto) do que os de produção, cujo trabalho consiste em controlar a tarefa concreta realizada por outros elementos humanos e determinada nos setores de planejamento. No caso desses últimos, todo o drama de "compreender" os operários ou realizar a contento os objetivos da companhia é muito mais pungente, e permeia seu quotidiano. Cremos que os supervisores de ferramentaria e os de controle de qualidade estão mais próximos do primeiro grupo (manutenção) do que do último. $O$ único caso de supervisor de segurança estudado nos pareceu mais inseguro e ambíguo que os de produção. Talvez isso se deva ao fato de que, embora exerça uma tarefa concreta, essa requer qualificação relativamente simples, que foi, neste caso, adquirida na própria empresa; uma das dimensões mais importantes de sua tarefa é justamente a de interferir nos maiores confrontos entre os trabalhadores e a empresa (greves, piquetes, ocupação da fábrica). Ademais, esse agente é o que apresenta a origem social e a escolaridade mais baixas de todo o grupo de supervisores estudados. tos:

Concentraremos nossa análise em três aspec-

- percepções sobre a própria trajetória e futuro profissionais; grau de reconhecimento em ralação à empresa;

- disposições em relação ao trabalho;

- relações com os subordinados e as chefias.

b) percepções sobre a própria trajetória e futuro profissionais; grau de reconhecimento em relação à empresa

A autovalorização profissional apresenta-se, em boa medida, negativamente correlacionada à gratidão manifestada em relação à empresa.

$O$ reconhecimento em relação à $X^{(7)}$ depende da posição do supervisor (setor), intimamente relacionada com sua escolaridade. Os cursos especiais, do SENAI e outros de nível técnico, ou de inglês, desempenham um papel quase tão importante quanto a educação formal, e os indivíduos se sentem menos gratos à empresa e mais confiantes em si mesmos nos casos em que os realizaram antes de entrar para a $X$, muitas vezes com o apoio de empresas em que trabalharam anteriormente. Da mesma maneira, a experiência profissional como fonte de aprendizagem ocupa um valor diferente, conforme tenha sido adquirida apenas na $X$ ou seja produto de experiências em outros empregos. A idade também influi na valorização da empresa. Todos esses fatores são, objetivamente, os determinantes que podem reforçar ou enfraquecer as possibilidades de encontrar uma situação profissional igual, melhor ou pior em outras empresas.

No ponto extremo de autoconfiança, temos o supervisor de manutenção de nível universitário, que está há pouco tempo na empresa e a trata instrumentalmente: se não alcançar o que deseja na X, irá procurar outra empresa, como já fez com as anteriores.

É o único caso em que aparecem queixas contra um sistema de compadrio e protecionismo, valorizando-se, contra isso, um "espírito profissional":

"Eu sou um profissional que prezo muito a minha condição, certo? Eu tenho até... uma instituição, um CREA, que rege os meus direitos, né? E como profissional eu me considero... um elemento de capacidade, uma capacidade de assimilação muito grande, qualquer sistema a gente entende... tem uma visão muito boa.

A gente sente uma coisa que é um mal, um grave mal lá dentro. O... o pessoal de chefia, superintendência, gerência, a gente nota que os maiores beneficiados são os parentes, os amigos, certo? Os funcionários que vão consertar televisão em casa, que vão dar um banhinho no cachorro da pa... da madame, certo? Isso é normal, toda noite sai um... Tem gente que vai procurar beneficiar os chefes em casa. Não resta dúvida que os primeiros beneficiados são esses, de uma forma ou de outra, né? E como eu já falei, eu prezo muito meu... minha qualidade profissional, eu acho que isso... é um mal que prejudica a $X^{\prime \prime}$.

Para este supervisor, a empresa é uma oportunidade para um aperfeiçoamento profissional ainda maior:

"Ambiente de trabalho muito bom (na X)... Principalmente convivência de pessoal. Eu já vinha com uma certa experiência de fora $e$ a gente sempre acaba aprendendo certas coisas novas, né?... O tipo de serviço que eu faço... sempre fui aficcionado a isso, desde criança. Para mim não é mais tanto uma profissão, mas é mais assim um hobby, um lazer, é 24 horas por dia, se eu pudesse eu respirava aquilo que faço. $E u$ gosto muito... entâo eu tenho inclusive vários colegas de fábrica com os quais troco idéias, né? Trocamos informação... inclusive são rádio-amadores. (O entrevistado tem um micro em casa). Nós trocamos informações, contatos, programas... é realmente um passatempo muito bom, a gente se diverte. Além disso, no serviço, a gente está sempre em contato com coisas no-

7. A empresa estudada receberá neste trabalho o nome de $X$. 
vas, novidades, né? Mesmo lá na $X$ a gente tem condições sempre de mexer, porque tem um bom laboratório, na Eletrônica, você tem sempre condições de mexer, fazer uma coisa nova, ou outra, certo? Ou de bolar alguma coisa diferente... em suma, a gente está sempre em contato com aquilo que a gente gosta de fazer... eu tive sorte com o pessoal que eu convivo lá dentro, tem o mesmo pensamento meu, certo?"

As avaliações positivas e negativas da empresa têm como contraponto a auto-imagem. A valorização profissional que esse supervisor faz de si mesmo permite-lhe comparar as diversas empresas nas quais já trabalhou e aquelas em que potencialmente pode vir a trabalhar, numa postura de quem é dono do próprio destino, de quem pode escolher. Ainda mais: no momento está concedendo um crédito de confiança para a $X$; se ela não corresponder às suas expectativas, irá procurar uma empresa melhor. Aqui, aparece invertida a questão do "período de experiência", durante o qual as empresas avaliam melhor o funcionário novo, para decidir finalmente se o aceitam em caráter definitivo:

"Eu acho que a $X$ oferece melhores recursos do que a maioria das fábricas. Talvez por ela ser uma metalúrgica grande, ela tenha condições de oferecer isso... se não oferece mais é por causa das próprias condiçōes econômicas do país. Isso eu falo porque peguei justamente a crise, né? Então senti, comecei a sentir realmente, o drama de todas as poucas fábricas que trabalhei... e acho que a melhor, a que está dando condições apesar de toda esta crise, ainda até agora foi a X. Estou satisfeito, certo? Espero comigo que, não sei se isso aí é um... talvez pode ser até um brio profissional meu, que eu... vou dar um tempo para mim mesmo, talvez até para a própria $X$, para que o meu serviço, o meu trabalho seja, vamos dizer assim, reconhecido, né? E... até esse tempo espero que... que eu possa atingir uma certa meta lá dentro, né? Se caso isso aí não acontecer, eu vou fazer como fiz com todas as outras firmas, certo? Eu, até hoje, graças a Deus, nunca, nunca fui mandado embora de nenhuma firma, sempre sai, nunca fiquei desempregado nem uma semana".

O outro universitário da pequena amostra de supervisores (igualmente engenheiro eletrônico), alocado na manutenção, embora explicite menos as coisas, tem uma atitude muito semelhante:

"Agora quanto à empresa, não conheço bem para falar (está na $X$ há pouco tempo), mas me parece que a X é uma empresa séria, dentro daquilo que eu tenho visto por ai, se preocupa com o pessoal e não sei... tenho esperança de talvez me desenvolver lá dentro".

Defendem, portanto, a "seriedade" e o "espírito profissional" porque só teriam a ganhar com isso; num sistema meritocrático, seus trunfos escolares e a competência profissional que acreditam possuir só lhes trariam vantagens.

Um supervisor de controle de qualidade que, apesar de ter uma escolaridade formal relativamente baixa, fez muitos cursos técnicos e declarou ter excelentes conhecimentos na área, foi o único a fazer uma associação entre a empresa e o produto que essa fabrica:

"Por exemplo, hoje em dia, tem que fazer melhor, porque a concorrência está cerrada $e o$ consumidor também está exigindo, não admite assim um produto malfeito. $A X, d a$ indústria automobilística nacional, não é porque eu trabalho na $X$ que eu vou dizer, mas é a indústria mais perfeita do carro nacional.".

(Explica longamente ao entrevistador que o antigo câmbio de um dos modelos de outra indústria era o melhor, hoje é o de um dos modelos da X; o menor custo de manutenção é o de outro modelo da $X$; por isso atingem melhor preço na revenda, etc.)

Como vemos, os supervisores de manutenção e o de controle de qualidade referem-se continuamente à competência profissional que colocam a serviço da $X$, à qualidade de execução de suas tarefas.

Por outro lado, o único supervisor de produção que enfatizou seu trabalho ilustrou suas qualidades profissionais pela dedicação, freqüência, boa-vontade e sacrifício. Paralelamente, aparece a gratidão exacerbada em relação à empresa.

"Bom, tem muita gente que não gosta do trabalho, gosta do emprego. Eu já penso de outra maneira. Para você manter um emprego, você precisa trabalhar. Essa é uma coisa que eu mesmo sempre digo: porque tem gente que só pensa no emprego e não no trabalho, $e$ eu já penso diferente, eu tenho que demonstrar alguma coisa, demonstrar boa-vontade, demonstrar responsabilidade, trabalhar com amor, porque se não...Querer emprego todo mundo quer, mas trabalhar eu acho que são poucos... e eu penso de uma maneira totalmente diferente. Tanto que no tempo... nesse tempo que eu trabalho na $X$, eu trabalho, eu trabalho a semana inteira, eu trabalho aos sábados, nunca me recusei a trabalhar, porque eu acho que é uma obrigação, uma... se eu dependo daquele trabalho, se eu disse antes, anteriormente, que se eu tenho alguma coisa é 
graças à companhia. Eu acho que tenho que retribuir com o meu sacrificio, certo?"

Interessante observar que, ao colocar a dicotomia emprego-trabalho, esse supervisor chegou a falar de gente que "não gosta do trabalho". Mas as associações seguintes se encaminharam crescentemente na direção de uma troca (para ter emprego é preciso trabalhar, demonstrar boavontade, trabalhar é uma obrigação e, finalmente, trabalhar é um sacrifício).

Não podemos perder de vista que a maioria dessas histórias de vida são histórias de ascensão ${ }^{(8)}$. O supervisor é aquele que foi escolhido entre operários para essa promoção. $O$ discurso livre se detém sempre na explicação desse fato. Evidentemente, a ascensão é atribuída, antes de mais nada, ao mérito, ao fato de ser melhor que os outros. Mas esse "ser melhor" pode estar se referindo mais a trunfos inquestionáveis e legítimos (diploma, competência, experiências anteriores) ou à maior dedicação e esforço, abnegação e sacrifício. Os supervisores de produção tendem mais ao segundo tipo de explicação, enquanto os de manutenção salientam mais o primeiro.

O reconhecimento em relação à empresa por essa ascensão está necessariamente mesclado ao sentimento de ser pessoalmente melhor que os outros. Porém essa combinação varia muito, desde o ponto extremo ocupado pelos supervisores que acham que podem encontrar a mesma coisa em outra companhia, até os casos que declaram dever "tudo à companhia". A gratidão total aparece nos indivíduos de baixa escolaridade, muito tempo de casa, treinamento interno à empresa, alocados nos setores de produção e segurança.

Nesses casos, o individuo chega a acreditar que a posição que alcançou, sua qualificação e tempo de serviço não valem nada lá fora, como é o caso do supervisor de segurança:

"Eu gostaria muito de me aposentar pela $X$. Se eu sair da X eu vou... vou ter que fazer tudo de novo".

A empresa é igualmente muito valorizada por aqueles que adquiriram conhecimentos, foram promovidos e fizeram cursos dentro da $X$, como os dois casos de supervisores de manutenção que entraram muito jovens (18 anos), sem trazer nenhuma bagagem de fora. Luc Boltanski ${ }^{(9)}$ detecta uma preferência das empresas pela contratação de quadros com diplomas não legítimos ou não diplomados, justamente por sua maior lealdade à empresa, e com o objetivo (talvez não inteiramente consciente) de levar o indivíduo a acreditar que a empresa é tudo para ele, porque lá fora ele continua não sendo nada.

c) disposições em relação ao trabalho

Poderíamos afirmar, pelo que sugerem as entrevistas em profundidade, que o supervisor de manutenção tem um verdadeiro trabalho e não apenas um emprego. Nos discursos livres, foi habitual, entre eles, a referência a uma "vocação" (geralmente desde criança) e a um interesse genérico pela área na qual trabalham.

No seu quotidiano, o supervisor de manutenção desempenha de fato uma tarefa, que não se reduz a passar ordens de cima para baixo e vigiar os operários. Ele fala menos de problemas humanos em relação aos subordinados, e mais de questões técnicas. É como se ele tivesse "assistentes" ou "ajudantes" menos qualificados que ele, e não propriamente subordinados. Por uma série de razões, o dia-a-dia está mais próximo de uma realidade pré-taylorista: o trabalho de manutenção não pode ser fragmentado nem especificado; sua equipe tende a respeitá-lo mais pelos conhecimentos técnicos do que pelo nível hierárquico. Sua promoção ao cargo se deve, de fato, a uma maior qualificação, está diretamente vinculada a maiores conhecimentos em relação à tarefa desempenhada pelo grupo.

Os supervisores de manutenção valorizam muito a competência técnica que possuem e encontram uma harmonização entre sua vocação, o que aprenderam e a tarefa que executam. Um deles se queixa da excessiva importância atribuída à máquina e diz que é preciso lembrar que ainda há partes artesanais, que o "homem é que arruma as máquinas". A percepção do caráter menos repetitivo e previsível da tarefa está presente, assim como a responsabilidade e a autonomia na tomada de decisões em relação à sua execução:

"O serviço até que é interessante, dentro da-

8. E preciso lembrar que o cargo de supervisor pode ser o corolário de toda uma carreira como operário, ou, ao contrário, o patamar para cargos administrativos ou técnicos mais elevados, nos casos de entrada lateral. A sofisticação tecnológica alcançada hoje na indústria automobilística leva à necessidade de se colocar na manutenção, controle de qualidade e ferramentaria quadros mais jovens e escolarizados, seja via entrada lateral, seja pelo aproveitamento de quadros internos que adquiriram qualificação paralelamente. Outros "pacotões" já devem ter varrido desses setores os supervisores mais velhos, de baixa escolaridade e muito tempo de casa, como os que ainda encontramos entre os supervisores de produção e de segurança. Isso explica nossa afirmação de que qualificação e escolaridade constituem pré-requisítos para a conquista dos cargos de supervisão nos setores de manutenção, controle de qualidade e ferramentaria.

9. BOLTANSKI, Luc. Op. cit. 
quilo que eu gosto, a gente nunca sabe o que vai encontrar pela frente... a linha está trabalhando, de repente surge um problema $e$ a gente tem que resolver o mais rapidamente possivel..."

Ao ser perguntado, no questionário que se segue ao discurso livre, sobre a tarefa, se ela era cansativa, enervante, etc., um supervisor de manutenção responde:

"Tudo depende de como o cara encara o serviço... se o tipo de serviço já é da pessoa, já é profissionalmente aquilo que espero que seja certo! Está dentro daquilo que eu acho que tem que ser. Trabalho, gosto do que faço, o trabalho, em si, eu acho fascinante. Para mim são horas que passam com extrema rapidez, né?"

A importância atribuída à capacidade na área leva a um discurso que não aparece entre outros supervisores, e que se refere a uma resistência ao excesso de mecanização, como inibidor da criatividade e da verdadeira aprendizagem. Falando do seu primeiro emprego, um supervisor de manutenção diz:

"Era uma oficina pequena e por incrivel que pareça é um lugar que você aprende. Firma grande facilita para você trabalhar, devido aos recursos que você tem. Para aprendizado tem que ser firma pequena. Firma pequena que eu digo é oficina, entende? Mesmo uma fábrica metalúrgica pequena também não te dá isso, ela tem uma série de facilidades que você não faz trabalho manual, tem máquina (...) numa oficina você não tem nada disso, você tem simplesmente uma bancada e um jogo de limas. Você tem que moldar alguma coisa no teu recurso pessoal, essa é a vantagem. Eu acho que todo mundo quando começa não tinha que ter uma máquina na mão (...) Na firma grande você tem uma máquina para tudo, quer dizer, você não é um profissional, profissional é a máquina $e$ não o ser humano. Para a indústria é vantagem porque ela agiliza a coisa, mas em termos pessoais o homem se sente muito deprimido. Ele não consegue colocar para fora a criatividade dele. $O$ que a gente está notando ná indústria é isso, que eles estão automatizando $e$ o homem está ficando para trás. Aprendi muita coisa numa firma pequena porque havia encarregados que não eram chefes, eram amigos. Quando você tinha qualquer dificuldade eles encostavam em você $e$ antes de chamar a atenção, primeiro mostravam como fazia. E eles também sabiam fazer, ao passo que hoje em dia você encontra muitas vezes pessoas acima que simplesmente sentam $e$ fazem no papel. Na $X$, atualmente, só sobe a grau 9 quem tiver faculdade, antigamente era $o$ indivíduo que realmente conhecia".

Ao ser inquirido sobre o trabalho, se gosta da tarefa, se ela é cansativa, etc., o mesmo entrevistado responde:

"Dizer que eu não gosto é mentira porque eu sempre gostei. De manutenção tudo o que vier eu faço. Dizer para você que não gosto é mentira porque eu já cheguei a fazer 72 horas sem sair de lá de dentro. Fazer 36 horas era normal... cansa o físico da gente, mas mentalmente a gente está fazendo aquilo que a gente gosta".

Além dessas percepções mais globais, que se referem à mecanização, tipo de chefia, imprevisibilidade da tarefa, possibilidade de aplicar as próprias aptidões e conhecimentos no trabalho, como indicam os trechos das entrevistas acima, os supervisores de manutenção apresentam uma postura mais reivindicativa em relação a questões internas à organização.

"Não sei se é só na X... mas no nosso sistema lá devia ser mais visada a manutenção, né? Como sempre foi, em qualquer setor industrial, né? A manutenção teria que ser, assim... mais bem servida. E lá parece que não é tanto assim, porque a gente não mede esforços, (faz) mais sacrifícios, a gente tem que estar lá pronto para tudo, certo? Porque é fácil, não sei se você me entende, né, é fácil para o pessoal de chefia, gerência, que talvez esteja pressionado pelos próprios chefes deles, chegar e falar assim: 'Olha, quero isto aqui funcionando amanhã', certo? '- Ô, mas como é que vamos fazer se não temos nem material, nem gente para fazer?' 'O problema é de vocês, se virem'. E isso obviamente não é reconhecido, não é visto nem reconhecido, né? essas coisas só são observadas quando não dão certo. Quando dão certo, o elogio vem para os próprios chefes".

Nesse grupo, apareceu também outro tipo de queixa em relação aos escalões mais altos mas, diferentemente da revolta genérica contra as vantagens daqueles que estão situados em posiçōes mais altas, aqui o critério de justiça se refere ao grau de conhecimentos na área e ao trabalho efetivamente realizado:

"Mesmo na área de Engenharia... a gente chega inclusive a ficar, às vezes, vamos dizer assim, revoltada, né? De ver um pessoal que está, vamos dizer assim, melhor que a gente... em termos de posição...dentro da própria indústria, não tem a minima... tem um terço praticamente do conhecimento que a gente tem, certo? Não resolvem nada... não fazem nada... profissionalmente têm melhores condições que a gente". 
Esses agentes percebem que seu trabalho conduz a um verdadeiro desenvolvimento profissional e postulam que a ascensão na hierarquia organizacional deveria estar mais diretamente vinculada a esse aperfeiçoamento, como ficou expresso no protesto, já citado, de um supervisor, contra o fato de só atingir certo grau na empresa "quem tem uma faculdade" e não os que realmente conhecem o assunto.

"A gente começa de baixo e vai crescendo, $e$ como a gente cresce no valor profissional, a gente é...sei lá, fica justo crescer também no valor do dinheiro, né?"

Nesse ponto, cumpre relembrar que, em todos os aspectos já abordados, o supervisor de controle de qualidade e o de ferramentaria se aproximam muito do supervisor de manutenção. Por exemplo, a importância do conhecimento fica bastante clara no discurso de um supervisor que já esteve no controle de qualidade, hoje é supervisor de produção, e explica por que prefere o primeiro setor:

"Eu gosto de trabalhar. Eu faço um trabalho que... não estou diretamente ligado ao ramo que eu gostaria de estar fazendo, sabe? Eu faço parte da supervisão da $X$, mas eu trabalho na produção, sendo que o meu ramo, o que eu mais me aprimorei, o que eu considero mais técnico, onde a gente aproveita um pouquinho mais aquilo que a gente estudou, né? Controle de qualidade aqui no Brasil não é uma função, não é uma profissão definida pela CLT, né? Mas é uma função muito importante..."

Esses aspectos foram bem explicitados por outro supervisor de controle de qualidade que, segundo informou, para acompanhar a evolução técnica fez praticamente todos os cursos do SENAI; fala de seu método de trabalho, que é diferente do dos outros, de como exige qualidade a cada passo, de quanto é caprichoso, como, a cada problema, tem que descobrir de quem é a responsabilidade, detalha tudo o que conta, enfatizando muito a dimensão técnica, usando termos técnicos (micron, computador de precisão, etc.), mostrando sempre seus conhecimentos em mecânica. Relata como, além dos problemas que surgem e que exigem solução imediata, existem outros que aparecem sempre e em relação aos quais é preciso estar sempre pesquisando para ver como resolvê-los.

Muito diferente dessa realidade é o dia-a-dia do supervisor de produção. Em seu discurso não aparece o que ele faz, nem do que gosta, nem o que conhece. Recorrentemente aparece a expressão: "o supervisor de produção é responsável por isso, por aquilo..." Recebe ordens de cima e deve transmiti-las para baixo, zelando para que sejam cumpridas. Tal planejamento de cima é diário, o que limita inteiramente sua margem de autonomia, que existiria num planejamento mais a longo prazo, como o schedule mensal (que existe, mas funciona apenas parcialmente no quotidiano). As poucas áreas de autonomia de que dispõe não se referem à dimensão técnica, mas a uma imprecisa "capacidade de lidar com pessoas" e com os problemas daí decorrentes. O desempenho do próprio supervisor é função direta do desempenho de seus funcionários. Essa categoria de supervisores parece sofrer, muito mais que as outras, a ambigüidade de se identificar com os "de baixo" (os operários, seu grupo de origem), e com os "de cima", em cujo espaço não chega realmente a se integrar. A empresa tenta aplacar os efeitos dessa inconsistência principalmente por duas vias: nos casos estudados, o indivíduo alçado à posição de supervisor muda de grupo, de maneira que não precisa "chefiar" seus antigos colegas; em segundo lugar, é alvo de treinamento intensivo de chefia e liderança, para reforçar sua pertinência ao grupo de chefia, aumentando o hiato em relação ao seu próprio passado ${ }^{(10)}$.

Nas funções que exerce, é mais um fiscal do que um profissional que conhece o trabalho melhor do que os seus subordinados.

Tudo isso está presente na resposta que um supervisor de produção dá à pergunta: "- O Sr. poderia descrever para mim o que é ser supervisor de produção?"

"Supervisor de produção funciona da seguinte forma: é o homem responsável pela quantidade de trabalho de um determinado número de funcionários. Esses funcionários são desde ajudantes até profissionais (enumera os diversos cargos e tarefas de seus funcionários). Então eu sou responsável por um determinado numero de homens que fazem todos esses tipos de trabalho. Durante o dia eu recebo uma quantidade de produtos a serem fabricados. Todos os carros $X$ passam lá. Então eu sou responsável pela produção de cada um desses itens. Eu recebo um número na parte da manhã, existe um programa mensal, então existe um schedule

10. Os treinamentos de chefia básica visam, para além de um aprimoramento em relações humanas, a reforçar, no quadro da ambigüidade de identificação do supervisor, uma "socialização" desse, como mostra DANTAS, Laura (op. cit.) e constituem parte importante dos "mecanismos de conquista da lealdade desses trabalhadores para com os objetivos da empresa" mencionados por BORJ, Bila no artigo "O Processo de Trabalho como Dóminação: um Estudo de Caso" in Dados, Rio de Janeiro, IUPERJ, vol. 24, $\mathrm{n}^{2} 3$, 1981. 
dentro da produção, que é o programa mensal. Mas dentro desse schedule existe uma variação, essa variação depende da quantidade de peças que o fornecedor consegue enviar para nós. Existe modificação de planos de trabalho, então esse schedule de produção fica praticamente nulo. Não fica nulo, porque é um programa que deve ser seguido, mas esse fica praticamente nulo para nós. Eu não posso me basear nele para começar meu trabalho do dia. Então existe um controle de produção, este controle diz para mim que vão sair tantos $A$, tantos $B$ duas portas, quatro portas, tantos $C$, tantos $D$, tantos $E$, né? $Q$ Quantos $F$ duas portas, quatro portas. $E$ dentro desses números que eu recebo, eu começo a fabricar as determinadas peças que tem na minha área. (11)

Além de ser responsável por esse tipo de trabalho, que é a produção, eu sou responsável pela organização da seção. A seção, apesar de estar trabalhando, deve ser organizada e ter uma aparência de ordem. Porque, se não, poderia, por exemplo, você fabrica uma coisa, pōe aqui, outra ali, então sou obrigado a me responsabilizar para que tenha uma... que o local seja mantido em ordem. Sou responsável pela segurança dos elementos da área, então sou obrigado a manter um diálogo de segurança, periodicamente, com os homens, tentando orientá-los da melhor forma possivel, quanto a evitar o acidente. Então, 0 importante não é, por exemplo, dizer para o sujeito: '- Olha, cuidado, não faz isso porque você vai se machucar'. É conscientizar para que cada coisa que ele faça, ele pense no fator segurança para trabalhar. Assim, somos responsáveis pela boa aparência do homem dentro do trabalho, não que a gente, quando o elemento está barbudo, diga para ele: "- Ô Fulano, você precisa cortar a barba aí. Não, não é nada disso. Mas se ele, por exemplo, trabalha com uma roupa muito suja, a gente tem condições de dizer: - Olha, Fulano, você precisa trocar a roupa'. E... a gente dentro do cargo de superoisão ainda a gente é responsável pela qualidade do produto do elemento, porque existe o funcionário que faz um bom trabalho e um mau trabalho, então a obrigação da gente é de cuidar para que o trabalho seja sempre perfeito. A gente é responsável pelos salários dos homens. A Companhia, é ela quem paga, mas quem determina quanto este funcionário deve ganhar é a supervisão. Está certo que é um processo, assim, que não sou eu que determino que, bom, a partir de amanhã ele vai ganhar tanto. A Companhia me dá uma margem $e$ eu trabalho sempre dentro daquela margem. Deixa eu ver se eu estou esquecendo mais alguma coisa que a gente tem responsabilidade. Ah! A gente tem responsabilidade quanto ao consumo de material näo produtivo, porque, por exemplo, para fazer um acabamento, o ho- mem tem que usar luva, o homem tem que usar, por exemplo, um disco de lixa para dar o acabamento da peça, então nós somos responsáveis para que esse material seja bem utilizado $e$ que o consumo seja pequeno. E apesar que nós temos que dar condições do material estar em boas condições para o funcionário trabalhar..."

Depois de falar como tem que contornar problemas, principalmente de doença e malandragem de seus subordinados, diz:

"E, se isso (problemas, doença, malandragem) acontece com um determinado numero de homens, todos os dias, a gente não consegue tirar produção. E se a gente não consegue tirar a produção, a gente sempre é taxado de incompetente, $e$ isso ai acho que ninguém gosta, né?"

Vê-se que a tarefa do supervisor de linha reside principalmente na "arte" de lidar com seus subordinados. Os resquícios de treinamento de "liderança democrática" aparecem nitidamente. A única área de relativa autonomia consiste na avaliação e na programação de férias dos homens sob sua chefia. Os supervisores valorizam muito seus "relatórios de avaliação". É provável que isso ocorra não só porque é uma tarefa mais intelectualizada, mas porque é uma verdadeira tarefa executada por eles, com uma maior margem de autonomia ${ }^{(12)}$.

d) relação com os subordinados

Mais uma vez, nessa dimensão aparecem as diferenças entre os supervisores de manutenção, controle de qualidade e ferramentaria, de um lado, e os de linha, de outro. Entre os primeiros, falar dos subordinados implica falar da tarefa, do grau de conhecimento sobre ela, etc. Entre os segundos, freqüentemente acontece o contrário: ao serem inquiridos sobre o trabalho, só colocam problemas interpessoais e humanos em relação aos subordinados. À pergunta sobre como sentia seu trabalho, um supervisor de produção respondeu:

"Esse trabalho é de grande responsabilidade, porque quando tudo corre bem, então está tudo bem, a gente vai para casa sossegado. Mas tem dias que a gente não consegue fazer, por exemplo, que tudo corra bem. Por exemplo, existem

11. Graças à programação eletrônica da montagem, o supervisor recebe o jogo das peças a serem utilizadas em cada automóvel na mesma sequêencia dos chassis dos diversos modelos enfileirados na esteira.

12. A maior resistência dos supervisores de produção à Comissão de Fábrica se explica, em parte, pelo fato de essa interferir muito justamente nessa parte de sua função (avaliação e promoção dos operários). 
funcionários, que é uma coisa comum, normalmente quem está de cima não sente, mas a pessoa ligada diretamente ao homem não deveria sentir, mas ele se vê na obrigação de sentir aquilo lá. Por exemplo, um elemento saiu de casa $e$ deixou um filho doente, esse elemento, ele vai trabalhar hoje, a reação dele não é uma reação normal, este homem está descuidado, está com risco de acidente, este homem às vezes tem chance de explodir, porque ele está nervoso, está tenso, e então nesse dia, às vezes por uma falha de outros, por exemplo, a gente acaba cometendo, assim, se levar a coisa a pulso, uma injustiça. Porque uma pessoa nervosa fala coisa que não deveria falar. Se a gente levar no seu lugar correto, a gente teria que tomar uma medida já mais drástica, dar uma suspensão ou qualquer coisa para o homem. Seria uma medida assim meio ruim. Isso se a gente não levar em consideração o homem, às vezes o homem chega lá $e$ diz assim: '- Olha, hoje eu estou com dor no ombro e eu não consigo fazer este serviço'. Agora eu, como supervisor da área, sou obrigado a fazer o trabalho, agora se o homem está com dor no ombro, o que eu faço? Ele diz que não pode trabalhar, eu digo para ele: '- Olha, então você vai no médico, lá, e diz para ele que você está com dor aqui'. Aí o médico vai lá, analisa o homem - o cara é meio malandro - o médico fala: - Olha, você não tem nada, pode voltar a trabalhar'. Ai ele fala: ' - Olha, o médico não me dispensou, não, mas eu não consigo trabalhar, como é que vamos fazer?' Então a gente fica numa situação ruim, então aí é que entra a responsabilidade da gente. A gente tem que conhecer o homem, porque às vezes o médico não dispensa ele, mas aquele homem está realmente doente. Existe aquele que é meio malandrão, então esse malandrão a gente é obrigado a tomar pulso firme e dizer: '- Ô Fulano, ou você faz ou não faz, não é?' Isso aí é uma coisa que às vezes a gente vem para casa e fica analisando. As vezes a gente passa por bobo, porque é obrigado a passar, porque se levar tudo a ferro e fogo, a gente não consegue levar a coisa para frente, nas boas condiçōes."

No trecho acima, o subordinado é tratado como "elemento" (quando está sendo visto de uma forma mais impessoal, a do operário que sai de casa para trabalhar), "homem" quando está sentindo algo (está nervoso, sujeito a acidente, a "explosões"), mais que isso, quando o narrador passa a perceber nele sentimentos, "cara" quando é preciso "tomar pulso firme", outra vez "homem" quando não conseguiu licença médica mas está doente de verdade.

O dilema do supervisor, pressionado a perceber as necessidades de seus subordinados e, ao mesmo tempo, a alcançar as metas organizacio- nais, tendo sido ele próprio um operário e tendo sua avaliação, hoje, atrelada à capacidade de "dar produção" (isto é, fazer os outros trabalharem), em suma, a divisão interna em que se situa talvez encontre uma válvula de escape numa divisão externa entre os "maus elementos" e os "bons funcionários".

O contraste entre supervisores de manutenção ou controle de qualidade e os de produção fica evidente nas três falas que reproduzimos a seguir (as duas primeiras, de supervisores de manutenção e a terceira, de supervisor de controle de qualidade):

"E... a gente está hoje realizado, eu me sinto realmente realizado porque hoje transmiti ao meu subordinado aqueles conhecimentos que a gente adquiriu através do tempo, através do interesse de buscar informação. Transmitir a eles em forma de correção um trabalho, e... coisas que se eu fosse somente um mecânico, um líder, a gente não teria condição, talvez não seria ouvido. Hoje, quando a gente faz uma correção de alguém sobre o lado profissional, a gente está convicto do que está fazendo."

"... acho que o conhecimento de mecânica cria condições que abrangem um campo muito maior... isso está valendo muito na $X$ também... sob meus cuidados tenho 16 homens e deles, dois terços são de mecânica e um de eletricistas. Então, eu... com os conhecimentos anteriores não fico assim... completamente alheio ao que acontece... acho que com o tempo tenho condições de assimilar tudo... E, como eu disse, é um vício, que nas horas de folga a gente vai praticando... porque a gente é obrigado a acompanhar a evolução técnica."

"Houve remanejamentos, né? Pessoal que trabalhava nas linhas que foram desativadas passou para outro setor. Dependendo do serviço que faziam, tem que fazer um treinamento, também, né? Porque até se adaptar não pode fazer serviço dificil, tem que começar com serviço mais fácil... o operário brasileiro se adapta fácil."

Como já salientamos, a fala dos supervisores de manutenção e de controle de qualidade está diretamente referida à tarefa, às condiçōes de se obter qualificação e conhecimentos, tanto no que se refere a si próprios como aos homens que supervisionam.

Para concluir, gostaríamos de enfatizar que a relação homem-tarefa, variável de maior poder explicativo para as diferenças encontradas neste trabalho, não deve correr o risco de ficar neutralizada, como ocorre em trabalhos que utilizam classificações mais genéricas como setor, ramo, nível tecnológico, departamento e nível hierárquico. $\square$ 